\title{
Estudos de casos sobre a avaliação do processo de gestão por secretárias municipais de saúde em dois municípios do estado da Bahia
}

\section{$\underline{\text { Shirlene Cerqueira dos Santos }}$; Silvone Santa Bárbara da Silva Santos²}

\author{
1. Bolsista PIBIC-Af/CNPq, Graduanda em Enfermagem, Universidade Estadual de Feira de Santana, e-mail: \\ Shirlene_cerqueira@hotmail.com \\ 2. Orientador, Departamento de Saúde, Universidade Estadual de Feira de Santana, e-mail: \\ silvone.santabarbara@gmail.com
}

PALAVRAS-CHAVE: Avaliação; Gestão; Secretários Municipais de Saúde.

\section{INTRODUÇÃO}

O conceito de gestão foi descrito pelo Ministério da Saúde (1996), como a atividade e a responsabilidade de comandar um sistema de saúde, exercendo as funções de coordenação, articulação, negociação, planejamento, acompanhamento, controle, avaliação e auditoria. (BRASIL, 1996).

É nítido que o processo de gestão da saúde está intimamente ligado ao sistema político em vigência, e esta situação é enfatizada quando Guimarães e outros (2004, p. 1646) afirmam que "a capacidade de gestão de uma organização social foi concebida como sendo a faculdade de uma organização em decidir com autonomia, flexibilidade e transparência, mobilizando recursos e construindo a sustentabilidade dos resultados de gestão".

A gestão em saúde abrange três grandes dimensões: os espaços dos cuidados diretos - singulares e multiprofissionais; as diversas instituições de saúde; e a exigência da formação e operação de redes de serviços de saúde para uma assistência universal, integral, equânime, de qualidade e eficiente para as necessidades de saúde da população (LORENZETTI et al., 2014).

Por estar diretamente relacionada ao processo político, a gestão em saúde sofre diversas modificações, o que muitas vezes acarreta na inexistência da qualidade do processo de trabalho das equipes assistenciais e na continuidade da oferta de produtos e serviços de saúde. Por isso, é imprescindível, que os gestores saibam articular de modo eficiente com as diferentes entidades, visando a melhoria dos serviços ofertados à população. Contudo, o que se observa muitas vezes, são gestores que por ocuparem os cargos de maneira "improvisada", agem com irresponsabilidade e descompromisso, justamente por não se identificarem com a função que lhes foi destinada (ARAÚJO; PONTES, 2012).

O estudo teve como objetivo, avaliar o processo de gestão por secretárias municipais de saúde através de estudos de caso múltiplos, em dois municípios do Estado da Bahia.

\section{METODOLOGIA}

Trata-se de uma pesquisa avaliativa com abordagem qualitativa, através de estudo de caso múltiplo. O estudo foi realizado em dois municípios do Estado da Bahia.

As participantes do estudo foram as gestoras que atenderam os seguintes critérios de inclusão: ser Secretária Municipal de Saúde (gestora máxima), coordenadoras (gestoras intermediárias) como Vigilância Epidemiológica, Assistência Farmacêutica, Atenção Básica, Centro de Apoio Psicossocial (CAPS), Saúde Bucal e Tratamento Fora de Domicílio (TFD). Sendo assim, participaram do estudo, sete gestoras do município 1 e sete gestoras do município 2, totalizando assim quatorze participantes. 
Em relação a escolaridade, todas as entrevistadas possuem o nível superior completo, nove eram enfermeiras $(64,28 \%)$, duas farmacêuticas $(14,28 \%)$, uma nutricionista $(7,1 \%)$, odontóloga $(7,1 \%)$ e uma psicóloga $(7,1 \%)$, três gestoras $(21,43 \%)$ do município 1 e uma gestora $(7,1 \%)$ do município 2 possuem especialização.

Para a análise das entrevistas utilizamos a abordagem proposta por Bardin (2011) e adaptado por Minayo (2010), evidenciado pelo fato de sua análise temática ser considerada mais conveniente as investigações qualitativas em saúde. Desta forma, analisamos os conteúdos em busca de colher enunciações avaliativas que seriam capazes de atender e direcionar a avaliação da capacidade de gestão por cada uma das dimensões de análise (organizacional, operacional e da sustentabilidade).

Esta pesquisa respeitou os aspectos éticos da Resolução no 466/12 do Conselho Nacional de Saúde (BRASIL, 2012), reservando aos participantes o direito de desistência em qualquer fase do estudo, sendo entregue o termo de consentimento livre e esclarecido, que foi assinado em duas vias.

\section{RESULTADOS E DISCUSSÃO}

Na dimensão organizacional, os municípios tiveram semelhanças e diferenças, não sendo atingido por ambos, nenhuma pontuação expressiva. Apesar de os municípios terem obtido o conceito "regular", no resultado total, o tema central "Capacitação formal", foi bem pontuado sendo atribuído o conceito "Muito bom", para ambos, o que demonstra a presença de um poder técnico ampliado, uma vez que a formação na área de gestão, qualifica o processo de trabalho das gestoras.

Em relação ao tema central, Participação na Comissão Intergestores Regional (CIR) " os resultados encontrados para os dois municípios não apresentaram diferenças significativas, demonstrando que para ambos é necessário que as gestoras atuam mais ativamente nesta comissão. Houveram diferenças no que tange ao processo decisório, pois o "município A" obteve o resultado "Regular", evidenciando que as decisões são tomadas com a participação de todas as gestoras, enquanto que o "município B", obteve o conceito "Ruim", por centralizar o poder nos níveis hierárquicos superiores (Prefeito).

Por fim, sobre a variável "Receita aplicada na saúde", ao "município A" foi atribuído o conceito "Regular", por estar evidenciado que o mesmo gasta mais do que a sua receita para os investimentos em saúde, enquanto que o "município B", consegue destinar os $15 \%$ exigidos por lei e ainda sim, dar resolutividade as suas demandas de saúde.

$\mathrm{Na}$ dimensão operacional, os municípios obtiveram como resultado o conceito "Regular", sendo que o tema central "Participação no Conselho Municipal de Saúde", foi o que mais se destacou para ambos os municípios, sendo conceituado como "Bom". Sobre as avaliações negativas obtidas nesta dimensão, onde todas as enunciações se opuseram a premissa, o "município A" obteve o conceito "Ruim" nos temas centrais "Vínculos Trabalhistas", revelando a não preocupação que o município possui acerca das relações trabalhistas que por ventura, possam vir a prejudicar a continuidade do serviço prestado pelos trabalhadores de saúde, enquanto que o "município B", obteve o conceito "Ruim" no tema central "Acompanhamento do Fundo Municipal de Saúde", revelando que as gestoras não se preocupam em acompanhar de perto se a destinação dos recursos está sendo feita de maneira correta.

Já na dimensão da sustentabilidade, ambos os municípios tiveram o conceito final "Regular", alcançando a mesma pontuação $(1,8)$, representando que os municípios estudados possuem estratégias para o aprimoramento de sua capacidade de gestão no intuito de sustentar os resultados alcançados através de suas ações, sinalizando para a capacidade de manter os resultados alcançados em médio e longo prazo, o que pode 
conferir o reconhecimento por parte da população. Podemos afirmar que, mesmo havendo temas centrais que foram avaliados positivamente, identificamos situações que constrangem a capacidade de gestão, e que se referem à participação das gestoras em discussões na câmara de vereadores, sendo necessária uma participação mais efetiva por parte da Secretaria Municipal de Saúde nas discussões do legislativo e que podem influenciar significativamente em decisões a serem tomadas dentro do setor saúde.

O gráfico 1 apresenta o resultado final da avaliação da capacidade de gestão dos municípios, com base nas dimensões de análise. Com base nos resultados finais das três dimensões avaliadas, podemos concluir que os dois municípios possuem características de gestão similares.

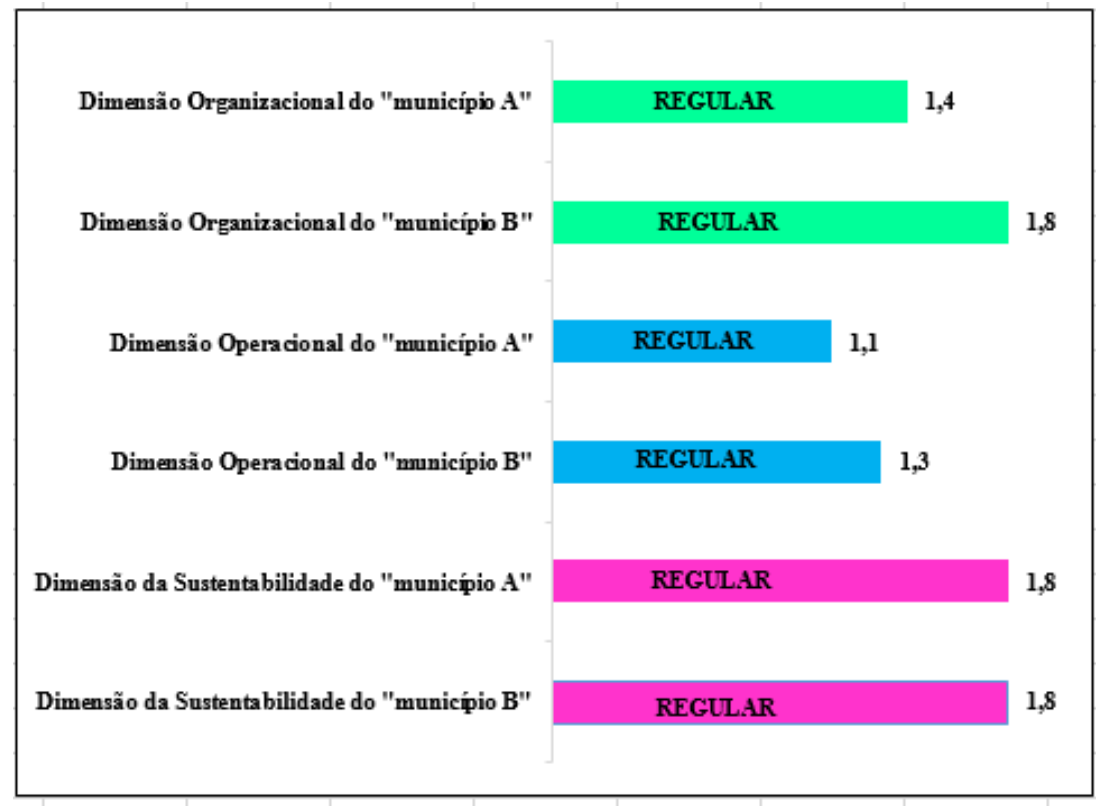

Fonte: Elaborado pela autora, 2018

Mesmo havendo pontos positivos no processo de capacidade de gestão dos municípios, ainda assim, não se verifica, de fato, uma gestão descentralizada por parte dos mesmos, sendo necessário o compartilhamento do processo decisório e a adoção de um planejamento orientado para as prioridades locais, inclusive, no que diz respeito à alocação de recursos financeiros e operacionais (SANTOS et al., 2018).

\section{CONSIDERAÇÕES FINAIS}

Os resultados apresentados sinalizam para vários constrangimentos no processo de gestão do SUS municipal. Dessa forma, ainda que tenha havido um equilíbrio entre as dimensões apresentadas, obtendo um conceito regular, entendemos que é preciso melhorar o processo de gestão em todas as dimensões avaliadas, observando-se as especificidades de cada município estudado.

$\mathrm{Na}$ dimensão organizacional (quem decide e como decide), chama atenção a falta de autonomia das gestoras durante o processo decisório, em função da centralização das decisões na figura da secretaria municipal de saúde, do envolvimento incipiente no referido processo por parte das gestoras intermediárias no processo decisório, além da participação limitada das gestoras dos dois municípios na Comissão Intergestores Regional.

No tocante a análise da dimensão operacional, esta foi entre as três dimensões a que recebeu as menores pontuações ("município A"- 1,1; "município B"-1,3), devido ambos municípios terem obtido as piores avaliações nas variáveis "Vínculos trabalhistas" e "Acompanhamento do Fundo Municipal de Saúde", evidenciando que 
não existe uma preocupação das gestoras acerca da precarização das relações de trabalho, bem como o não acompanhamento da destinação dos recursos financeiros por parte das gestoras, pode impactar significativamente na continuidade de programas e políticas públicas do setor saúde.

Como limitação do estudo, sabemos que por se tratar de estudos de casos, os resultados encontrados basearam-se em um momento pontual pelo qual os municípios estavam vivenciando, sendo este o retrato de um dado momento social, econômico, político e histórico, não sendo possível fazer generalizações, além de que, sinalizamos a não realização de um estudo de caso em um dos municípios selecionados por não aceitação dos gestores em participar desta pesquisa.

O recurso viabilizado pela Fapesb, através do projeto maior, garantiu a realização deste trabalho, revelando a importância das instituições de fomento à pesquisa na construção do conhecimento. Este estudo sinaliza para outras pesquisas, que poderão permitir generalização dos resultados e consolidação do modelo teórico elaborado para esta avaliação.

\section{REFERÊNCIAS}

ARAÚJO, C.E.L; PONTES, R.J.S. 2012. Constituição de sujeitos na gestão em saúde: avanços e desafios da experiência de Fortaleza. Ciência \& Saúde Coletiva, Rio de Janeiro. 17(9):2357-65.

BARDIN, L. Análise de conteúdo. Tradução Luís Antero Reto, Augusto Pinheiro. São Paulo: Edições 70, 2011.

BRASIL. Norma Operacional Básica do Sistema Único de Saúde. Diário Oficial da República Federativa do Brasil, Brasília, DF, 1996.

BRASIL Ministério da Saúde. Conselho Nacional de Saúde. Resolução 466 de 12 de dezembro de 2012: diretrizes e normas regulamentadoras da pesquisa envolvendo seres humanos. Brasília, 2012.

GUIMARÃES, M.C.L et al. Avaliação da capacidade de gestão de organizações sociais: uma proposta metodológica em desenvolvimento. Cad. Saúde Pública. Rio de Janeiro. 20(6):1642-50, nov-dez, 2004.

LORENZETTI, J et al. Gestão em saúde no Brasil: diálogo com gestores públicos e privados. Texto \& contexto enferm. 23(2):425-425, Apr-Jun, 2014.

MINAYO, M.C.S. O desafio do conhecimento: pesquisa qualitativa em saúde. 12 ed. São Paulo: HUCITEC, 2010.

SANTOS, S.S.B.S et al. Estudo de linha de base avaliativa sobre capacidade de gestão descentralizada da Vigilância Epidemiológica. Saúde Debate, Rio de Janeiro, v. 42, n. 116, p. 73-86, jan-mar, 2018. 